\title{
Cara siswa menyelesaikan masalah suhu dan kalor dari sudut pandang
}

\section{keterampilan metakognisi}

\author{
Susanti Rahayu $\left.{ }^{1 *}\right)$, Supriyono Koes- $\mathrm{H}^{2}$, Siti Zulaikah ${ }^{2}$, Ninik Munfarikha ${ }^{3}$ \\ ${ }^{1}$ Pascasarjana Pendidikan Fisika, Universitas Negeri Malang, Jl. Semarang No. 5, Malang, Indonesia \\ ${ }^{2}$ Jurusan Fisika, Universitas Negeri Malang, Indonesia, Jl. Semarang No. 5, Malang, Indonesia \\ ${ }^{3}$ SMA Islam NU Pujon, Jl. Abd Manan Wijaya No. 33, Malang, Indonesia \\ *Penulis korespondensi, e-mail: susanti070791@gmail.com
}

\begin{abstract}
The ways students solve problems become one of the main target of physics learning. Investigation about how students solve problems is explored in the context of metacognition skills. The steps of metacognition skills in physics problem solving include: planning, monitoring, evaluation, and controlling. This is a preliminary exploration study that aims to: 1.) mapping the metacognition skills that are used in physics problem solving of temperature and heat, 2.) exhibiting students' self evaluation of his/her metacognition skills in problem solving, and 3.) identifying the relationship between students answer and their self evaluation. This is a descriptive qualitative study. The data were obtained by test and questionnaire. The physics problem solving test was given to 35 students of $11^{\text {th }}$ grader. After doing test, they filled the 22 items of questionnaire adapted from Physics Metacognition Inventory (PMI). The result shows that none of the students solved all the problems optimally. The result of questionnaire showed that the average of metacognitive skills 64\%, with the maximum and the minimum scores is $87 \%$ and $35 \%$ respectively. The correlation between the analyses of students' answer and their self evaluation shows a negative value that indicates no relationship. Specifically, students pass the planning and controlling phase quite well, even though they tend to be poor in monitoring and evaluation. This findings must become a particular attention for the researchers and teachers in providing the learning strategy to habit the phases of metacognition skills in order to improve students' metacognitive skills.
\end{abstract}

Key Words: metacognition skill; problem; temperature and heat

\begin{abstract}
Abstrak: Cara siswa dalam menyelesaikan masalah menjadi salah satu sasaran utama dalam pembelajaran fisika. Penelusuran mengenai bagaimana cara siswa menyelesaikan masalah dieksplorasi dalam konteks keterampilan metakognisi. Tahapan keterampilan metakognisi dalam menyelesaikan masalah fisika meliputi: planning, monitoring, evaluation, dan controlling. Penelitian ini merupakan studi eksplorasi awal bertujuan untuk: 1.) memetakan keterampilan metakognisi yang digunakan siswa dalam menyelesaikan masalah fisika pada materi Suhu dan Kalor, 2.) menunjukkan penilaian diri siswa terhadap keterampilan metakognisi yang dimiliki dalam menyelesaikan masalah, dan 3.) mengidentifikasi hubungan antara analisis jawaban siswa dan penilaian diri. Penelitian ini merupakan penelitian deskriptif kualitatif. Data penelitian diperoleh melalui tes dan angket. Tes yang digunakan merupakan soal problem solving, yang diberikan kepada 35 siswa kelas XI. Setelah mengerjakan soal, siswa mengisi angket yang terdiri dari 22 item yang diadaptasi dari Physics Metacognition Inventory (PMI). Hasil penelitian menunjukkan belum ada siswa yang optimal menyelesaikan seluruh soal. Angket penilaian diri menunjukkan skor rerata $64 \%$, dengan skor maksimum dan minimum masing-masing $87 \%$ dan $35 \%$. Hubungan antara analisis jawaban siswa dan hasil penilaian diri menunjukkan nilai korelasi negatif yang mengindikasikan tidak sinkronnya hasil jawaban dan penilaian diri siswa. Secara spesifik, tahapan
\end{abstract}

How to Cite:

Rahayu, S. (2018). Cara siswa menyelesaikan masalah suhu dan kalor dari sudut pandang keterampilan metakognisi. Momentum: Physics Education Journal, 2(2). https://doi.org/10.21067/mpej.v1i1.2219

This is an open access article under the CC BY license (http://creativecommons.org/licenses/by-nc-nd/4.0/) https://doi.org/10.21067/mpej.v1i1.2219 
planning dan controlling dilakukan siswa dengan cukup baik, akan tetapi siswa cenderung lemah dalam memonitoring dan mengevaluasi ketika menyelesaikan masalah. Temuan ini menjadikan perhatian khusus untuk peneliti dan guru dalam menyajikan strategi belajar untuk membiasakan tahapan dalam keterampilan metakognisi dengan target peningkatan keterampilan metakognisi siswa.

Kata kunci: keterampilan metakognisi, masalah, suhu dan kalor

\section{Pendahuluan}

Metakognisi dikenal sebagai cara berpikir yang sangat penting dalam keberhasilan seseorang menyelesaikan masalah (Siegel, 2012). Selain itu, keterampilan ini menjadi salah satu keterampilan penting yang membekali siswa di kehidupan abad 21 (Mansour, 2016). Usaha pemerintah melalui Kementrian Pendidikan dan Kebudayaan menyisipkan keterampilan metakognisi menjadi salah satu keterampilan yang dimiliki siswa di dalam kurikulum.

Kajian metakognisi dimulai dari psikologi kognitif. Menurut Flavel, metakognisi adalah kognisi mengenai kognisi (Flavell, 1979). Metakognisi secara ringkas dapat diartikan sebagai cara berpikir seseorang (Abdullah, et al., 2013). Tidak hanya di bidang psikologi, metakognisi menjadi salah satu isu utama pada pendidikan sains.

Pentingnya keterampilan metakognisi, tidak diimbangi kemudahan untuk mendeteksi keterampilan tersebut. Penelitian menunjukkan ada dua cara mendeteksi keterampilan metakognisi dilihat dari waktu penggunaannya, yaitu on-line dan off-line assessment. Penilaian on-line dilakukan ketika siswa menggunakan keterampilan metakognisi dalam menyelesaikan masalah. Sementara penilaian off-line dilakukan ketika tidak sedang menyelesaikan masalah. Kedua penilaian tersebut digunakan untuk mendeteksi keterampilan metakognisi (Ozturk, 2017). Penelitian telah dilakukan oleh Schellings, et al. (2013) dengan membandingkan hasil penilaian angket dan dan think aloud protocols secara umum.

Komponen keterampilan metakognisi mengalami perkembangan dari beberapa penelitian. Pada pendidikan sains, keterampilan metakognisi dibagi dalam 4 aspek, yaitu planning, monitoring, evaluating, dan contolling (Zohar \& Barzilai, 2013). Pada pembuatan inventori Taasoobshirazi \& Farley (2013) mengkategorikan komponen keterampilan metakognisi menjadi pengetahuan kognisi (declarative, conditional, dan procedural) dan regulasi kognisi (planning, monitoring, evaluating, debugging, dan manajemen informasi). Komponen-komponen ini kemudian dijadikan sebagai dasar dalam pembuatan angket Physics Metacognition Inventrory (PMI) (Taasoobshirazi,et al., 2015).

Pertimbangan lain yang digunakan di dalam memilih instrumen penelitian keterampilan ini adalah banyaknya subjek penelitian. Angket dapat digunakan untuk banyak subjek penelitian. Akan tetapi kredibilitas penggunaan angket sering menjadikan hasil penelitian kurang dapat dipercaya. Untuk mengatasi hal ini, analisis jawaban penyelesaian masalah siswa dapat dijadikan data pendukung. Penelitian ini terfokus untuk: 1.) Memetakan keterampilan metakognisi yang digunakan siswa dalam menyelesaikan masalah fisika pada materi Suhu dan Kalor, 2.) Menganalisi penilaian diri siswa terhadap keterampilan metakognisi yang dimiliki dalam menyelesaikan masalah, dan 3.) Keterkaitan antara analisis jawaban siswa dan penilaian diri melalui angket.

\section{Metode}

Penelitian kualitatif dipilih agar dapat mendeskripsikan bagaimana siswa menyelesaikan masalah secara detail (Devetak et al., 2010). Masalah yang diselesaikan terkait dengan materi Suhu dan Kalor. Data penelitian diambil pada pekan ke-2 bulan Januari 2018 di SMA Islam NU Pujon, Kabupaten Malang. Data yang dikumpulkan berupa lembar cara siswa menyelesaikan masalah dan penilaian siswa terkait kemampuan diri. Dua instrumen ini digunakan karena tidak cukup hanya satu instrumen saja dapat digunakan untuk mengukur keterampilan metakognisi (Akturk \& Sahin, 2011). Terdapat 35 siswa kelas XI yang telah belajar materi Suhu 
dan Kalor. Siswa diminta menyelesaikan 3 soal problem solving terkait materi (Maliki, 2017). Hasil jawaban siswa di analisis melalui rubrik indikator metakognisi yang diadaptasi dari McCord (2014). Hasil analisis ini akan dipetakan dalam tiga kategori jawaban siswa: 1, 2, dan 3. Siswa dengan kategori 1 dapat menunjukkan komponen keterampilan metakognisi yang dimiliki dalam cara siswa menyelesaikan masalah dengan baik. Kategori 2 merupakan siswa yang memunculkan komponen metakognisi dalam mengerjakan soal akan tetapi tidak optimal. Tidak adanya komponen metakognisi pada jawaban siswa masuk pada kategori 3. Setelah siswa menyelesaikan 3 soal problem solving, siswa mengisi angket penilaian diri terkait kemampuan metakognisi yang dimiliki. Angket ini merupakan Physics Metakognition Inventory (PMI) yang diadaptasi sesuai dengan karakteristik soal (Taasoobshirazi, et al., 2015). Hasil PMI dikorelasikan dengan hasil analisis jawaban siswa untuk mengetahui hubungan antara penilaian diri dan hasil analisis jawaban siswa.

\section{Hasil dan Pembahasan}

Cara siswa menyelesaikan 3 soal problem solving dipetakan dalam 3 kategori seperti terlihat pada Tabel 1. Siswa kategori 1 dapat menyelesaikan masalah dengan benar menggunakan keterampilan metakognisi yang dimiliki. Siswa yang telah menggunakan keterampilan metakognisi tetapi belum maksimal sehingga jawaban akhir cenderung keliru masuk pada kategori 2. siswa yang tidak memperlihatkan keterampilan metakognisisnya dalam menyelesaikan masalah masuk adalah siswa kategori 3.

Secara komprehensif, belum ada siswa yang berhasil menerapkan setiap komponen metakognisi untuk mngerjakan semua item soal. Hanya ada 5 siswa (14\%) dari seluruh siswa yang menggunakan secara optimal pada item soal nomor 1.

Tabel 1. Pemetaan Analisis Jawaban Siswa Berdasarkan Komponen Keterampilan Metakognisi pada Tiap Item Soal

\begin{tabular}{|c|c|c|c|c|}
\hline \multicolumn{5}{|c|}{ Item soal 1} \\
\hline Kategori & $\mathbf{P}$ & M & $\mathbf{E}$ & \\
\hline 1 & $100 \%$ & $40 \%$ & $14 \%$ & \\
\hline 2 & $0 \%$ & $60 \%$ & $54 \%$ & \\
\hline 3 & $0 \%$ & $0 \%$ & $31 \%$ & \\
\hline \multicolumn{5}{|c|}{ Item soal 2} \\
\hline Kategori & $\mathbf{P}$ & M & $\mathbf{E}$ & C \\
\hline 1 & $100 \%$ & $11 \%$ & $0 \%$ & $100 \%$ \\
\hline 2 & $0 \%$ & $89 \%$ & $0 \%$ & $0 \%$ \\
\hline 3 & $0 \%$ & $0 \%$ & $100 \%$ & $0 \%$ \\
\hline \multicolumn{5}{|c|}{ Item soal 3} \\
\hline Kategori & $\mathbf{P}$ & M & $\mathbf{E}$ & C \\
\hline 1 & $60 \%$ & $0 \%$ & $0 \%$ & $54 \%$ \\
\hline 2 & $40 \%$ & $97 \%$ & $0 \%$ & $43 \%$ \\
\hline 3 & $0 \%$ & $3 \%$ & $100 \%$ & $3 \%$ \\
\hline
\end{tabular}

Seluruh siswa sangat baik melakukan tahap planning. Pada saat menyelesaikan soal nomor 1 dan 2, seluruh siswa dapat menuliskan besaran fisika yang ada pada soal dan memilih prinsip fisika yang cocok untuk menyelesaikan soal. Akan tetapi hanya $60 \%$ siswa yang berhasil mem-planning pada soal nomor 3 .

Item soal nomor 3 ini menuntut siswa untuk dapat menggabungkan konsep Azas Black yang terjadi pada beberapa peristiwa ketika percampuran dua zat dengan massa, jenis zat, wujud zat, dan suhu yang berbeda. Sebagian siswa tidak menuliskan informasi besaran fisika dengan lengkap. Selain itu, beberapa siswa keliru dalam menjabarkan prinsip fisika yang dipilih.

Pada tahap monitoring, pada setiap item soal sebagian siswa masuk pada kategori 1, bahkan pada item soal nomor 3, hampir semua siswa berada pada kategori ini. Tahapan ini terkait dengan proses berfikir 
siswa selama menyelesaikan masalah. Langkah perhitungan matematis dan pemahaman konsep fisis berperan penting pada tahap ini.

Tahap evaluation terlihat ketika siswa menyimpulkan jawaban yang diperoleh pada tahap-tahap sebelumnya. Akibatnya, tahap ini sangat dipengaruhi oleh keberhasilan siswa pada tahap-tahap sebelumnya. Pada item soal nomor 1, lebih dari separuh siswa masuk pada kategori 2, dan hanya $14 \%$ siswa yang dapat optimal menyimpulkan jawaban. Ketika siswa keliru dalam melakukan tahap monitoring, maka siswa tidak dapat optimal pada tahap evaluasi. Hal ini disebabkan karena kesimpulan yang diperoleh siswa merupakan hasil dari awal siswa melakukan planning, monitoring, bahkan contolling. Tahap evaluation lebih jelas terlihat pada saat siswa mengerjakan item soal nomor 2 dan 3. Semua siswa masuk pada kategori 3 yang berarti semua siswa tidak optimal dalam menyimpulkan jawaban yang diperoleh. Tidak dapat dipungkiri, faktor tingkat kesukaran dan kompleksitas soal mempengaruhi tahap evaluasi.

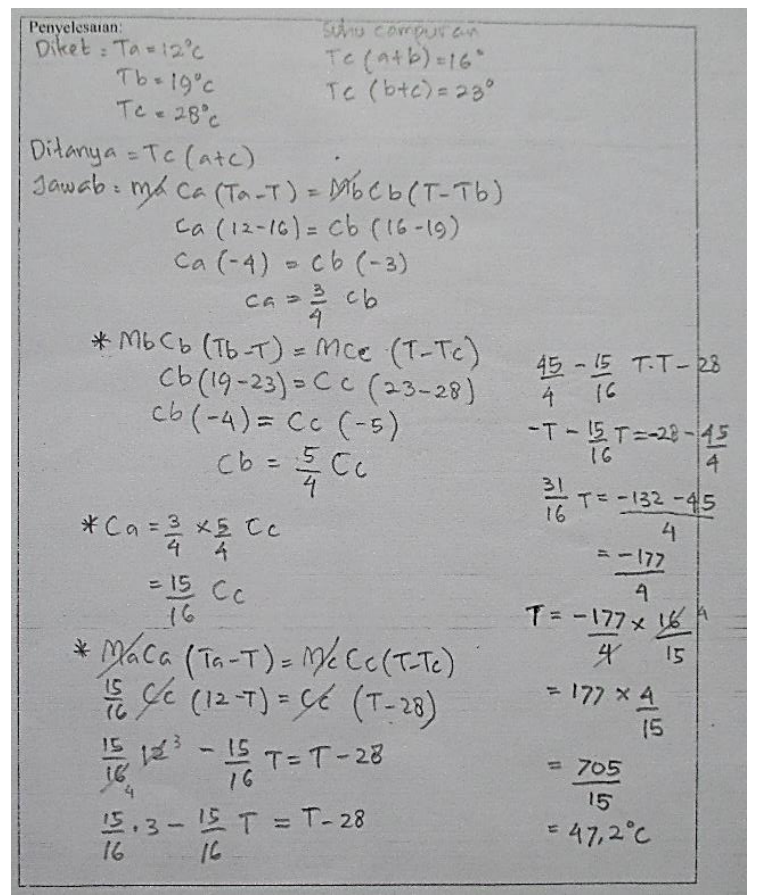

\section{Gambar 1. Penyederhanaan Matematis Ketika Penyelesaikan Item Soal Nomor 2}

Controlling terjadi mulai dari monitoring hingga evaluation. Tahapan ini dapat dilihat dari cara pengerjaan siswa untuk item soal yang membutuhkan menyederhanaan matematis dan menggabungkan beberapa konsep fisika dalam menyelesaikannya. Pada penelitian kali ini, item soal nomor 1 tidak dapat dilihat tahap controlling karena pada nomor ini tidak memerlukan penggabungan konsep dan penyederhanaan matematis. Gambar 1 memperlihatkan penyederhanaan matematis ketika menyelesaikan item soal nomor 2. Pada item soal nomor 3, terdapat $43 \%$ siswa kurang optimal dalam melakukan controlling. Kekurangoptimalan siswa ditunjukkan saat siswa keliru dalam menterjemahkan konsep fisika pada saat memasukkannya ke dalam hukum fisika yang dipilih ketika planning (Gambar 2a). Penyelesaian pada Gambar $2 \mathrm{~b}$ menunjukkan jawaban yang mempergunakan keterampilan metakognisi secara optimal. Siswa ini dapat membuat diagram kalor untuk mempermudah dalam memahami soal dan menggabungkan konsep fisika sesuai keadaan zat.

Selanjutnya, diperoleh sebaran data hasil penilaian pribadi siswa terhadap kemampuan metakognisi yang dimiliki melalui PMI (Tabel 2). Rata-rata siswa hanya menggunakan $64 \%$ dari semua kemampuan metakognisi yang dimiliki dalam menyelesaikan masalah. Persentase terbesar siswa berada pada subkomponen debugging (79\%). Debugging ini berkaitan dengan cara siswa mengoreksi pembelajaran dan kekeliruan dalam menyelesaikan masalah (Taasoobshirazi \& Farley, 2013). Siswa bertanya kepada guru ataupun teman ketika menemui kesulitan dalam menyelesaikan masalah yang dikerjakan pada tahap ini. 
Tabel 2. Hasil Analisi PMI pada Tiap Komponen Metakognisi

\begin{tabular}{|c|c|}
\hline Komponen & Persentase (\%) \\
\hline $\begin{array}{l}\text { 1. Pengetahuan Kognisi: } \\
\text { - declarative } \\
\text { - procedural } \\
\text { - conditional }\end{array}$ & $\begin{array}{l}63 \\
55 \\
55\end{array}$ \\
\hline 2. Regulasi Kognisi: monitoring & 58 \\
\hline 3. Regulasi Kognisi: evaluation & 61 \\
\hline 4. Regulasi Kognisi: debugging & 79 \\
\hline 5. Regulasi Kognisi: planning & 64 \\
\hline Rata-rata & 64 \\
\hline
\end{tabular}

Pada sub-komponen procedural dan conditional siswa memperoleh skor yang sama rendah (55\%). Sub-komponen procedural memperlihatkan bagaimana siswa menerapkan strateginya dalam menyelesaikan masalah, sedangkan kapan dan alasan siswa dalam menggunakan strategi untuk menyelesaikan masalah termasuk pada sub-komponen conditional.

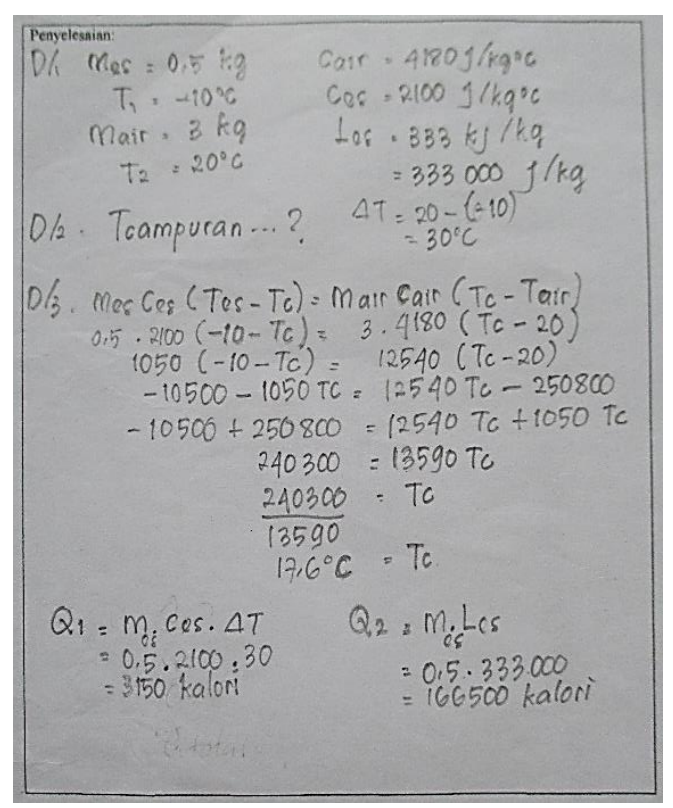

(a) 


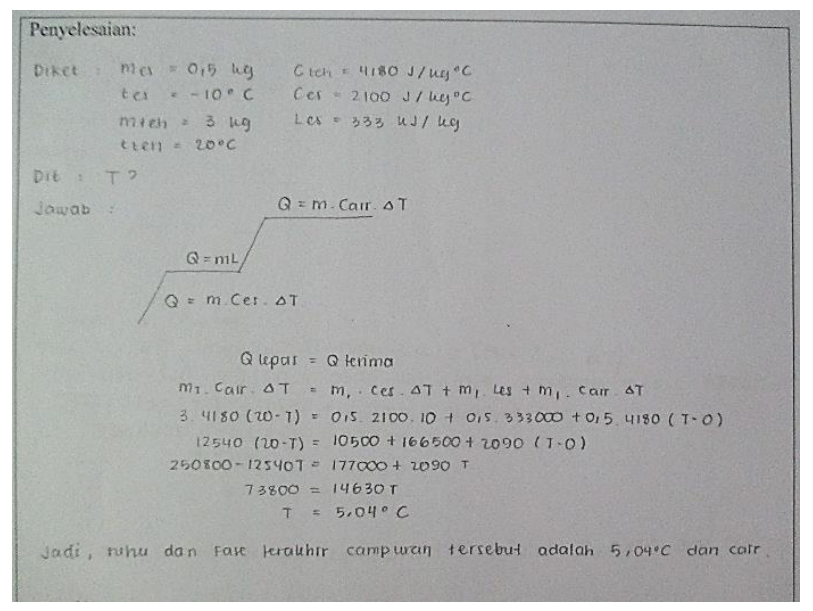

(b)

\section{Gambar 2. Jawaban siswa untuk item soal nomor 3; (a) kurang optimal; (b) jawaban yang benar}

Hubungan antara hasil analisis jawaban siswa dan PMI diperoleh melalui korelasi antara keduanya menggunakan Ms. Excel. Koefisien korelasi ( $r$ ) sebesar -0,5 termasuk pada kategori tinggi (Leech, et.al., 2005), tetapi nilainya negatif. Angka ini menunjukkan adanya hubungan yang tidak sebanding antara analisis jawaban siswa dan menilaian diri siswa terkait komponen keterampilan metakognisi yang digunakan saat mengerjakan masalah materi Suhu dan Kalor. Siswa yang cukup baik dalam menyelesaikan masalah cenderung tidak yakin akan kemampuan diri. Sebaliknya, siswa yang kurang baik dalam menyelesaikan masalah, menilai baik akan kemempuan dirinya. Hal ini memperlihatkan kemampuan monitoring siswa yang rendah akan kemampuan dan penilaian diri. Hasil korelasi dengan angka korelasi rendah hingga tinggi sebelumnya telah ditemukan (Schellings et al., 2013). Schellings et al., juga menemukan nilai korelasi negatif pada bagian dari komponen aktivitas metakognisi.

Hasil korelasi ini berlainan dari hasil penelitian yang memperlihatkan pengaruh positif antara kemampuan pemecahan masalah dan metakognisi siswa pada kelas fisika, baik strategi (Shareeja \& Gafoor, 2014; Harandi, et al., 2013) maupun keterampilan (Anandaraj, S. \& Ramesh, C., 2014). Hasil ini memperlihatkan siswa yang memiliki kemampuan penilaian diri siswa yang berkorelasi positif dengan analisis jawaban penyelesaian masalah menunjukkan adanya kemampuan siswa dalam menilai kemampuan diri. Kemampuan penilaian diri siswa sangat bergantung dengan individu sebagai pemilik monitoring diri.

Schraw et al. (2006) menunjukkan 6 instruksi strategi umum yang dapat digunakan untuk memunculkan beberapa kemampuan, termasuk di dalamnya metakognisi. Di dalam kelas, guru dapat bertindak berperan menjadi role model sebagai individu yang menggunakan kemampuan metakognisi dalam proses pembelajaran (Wall \& Hall, 2016). Aktivitas guru yang menggunakan leterampilan metakognisi didalam kelas dapat menjadi contoh bagi siswa. Siswa yang terbiasa merefleksi kemampuan metakognisi memiliki efek positif terhadap hasil belajarnya (Bannert \& Mengelkamp, 2008). Beberapa temuan penelitian tersebut dapat digunakan sebagai pertimbangan dalam rangka menyusun strategi pembelajaran yang dapat meningkatkan keterampilan meakognisi siswa.

\section{Simpulan}

Kemampuan siswa menyadari kemampuan yang dimiliki terkait keterampilan metakognisi dalam menyelesaiakan masalah dapat digunakan sebagai motivasi siswa dan guru. Kesadaran siswa akan belum optimalnya kemampuan yang harus dimiliki dapat termotivasi untuk upgrading. Sementara, penelitian selanjutnya tidak berlebihan ketika menampilkan cara yang dapat dilalui guru untuk meningkatkan setiap subkomponen keterampilan metakognisi dalam menyelesaikan masalah. Walaupun tidak dapat dipungkiri, kompleksitas keterampilan metakognisi sulit untuk dimiliki siswa secara menyeluruh. Hal ini menjadikan 
gagasan untuk penelitian selanjutnya untuk memunculkan langkah-langkah strategis dalam menyelesaikannya.

\section{Daftar Rujukan}

Abdullah, H., Malago, J. D., Bundu, P., \& Thalib, S. B. (2013). The use of metacognitive knowledge patterns to compose physics higher order thinking problems. Asia-Pacific Forum on Science Learning and Teaching, 14(2), 1-12.

Akturk, A. O., \& Sahin, I. (2011). Literature review on metacognition and its measurement. Procedia - Social and Behavioral Sciences, 15, 3731-3736.

Anandaraj, S. \& Ramesh, C. (2014). A Study on the Relationship Between Metacognition and Problem Solving Ability of Physics Major Students. Indian Journal of Applied Research, 4(5), 191-199.

Bannert, M., \& Mengelkamp, C. (2008). Assessment of metacognitive skills by means of instruction to think aloud and reflect when prompted. Does the verbalisation method affect learning ?, 3, 39-58.

Devetak, I., Glažar, S. A., \& Vogrinc, J. (2010). The Role of Qualitative Research in Science The Role of Qualitative Research. Eurasia Journal of Mathematics, Science \& Technology Education, 6(1), 77-84.

Flavell, J. H. (1979). Metacognition and Cognitive Monitoring A New Area of Cognitive - Developmental Inquiry. American Psychologist, 34(10), 906-911.

Harandi, V., Eslami, S. H., Ahmadi D. M., \& Darehkordi, A. (2013). The Effect of Metacognitive Strategy Training on Social Skills and Problem - Solving Performance. Journal of Psychology \& Psychotherapy, $3(4), 1-4$.

Maliki, I. M. (2017). Kemampuan Pemecahan Masalah dan Penguasaan Konsep Peserta Didik SMA pada TopikSuhu da Kalor Melalui Strategi Pembelajaran Cognitive Apprenticeship. (Unpublished master's thesis).Malang. Pascasarjana Universitas Negeri Malang

Mansour, N. (2016). Learning and Teaching in the Knowledge Society: Challenges and Potentials. Paper presented at: International Conference on Education by theme Education in the 21 th Century: Responding to Current Issues. Universitas Negeri Malang, 22-24 November 2016. Malang: Indonesia

McCord, R. E. (2014). Thinking About Thinking in Syudy Group: Sudying Engineering Students' Use of Metacognition in Naturalistic Settings. (Unpublished doctor's dissertation). Blacksburg. Virginia Polytechnic Institute and State University.

Leech, N. L., Barrett, K. C., \& Morgan, G. A. (2005). SPSS for Intermediate Statistics: Use and Interpretation. Mahwah, New Jersey: Lawrence Erlbaum Associates.

Ozturk, N. (2017). Assessing Metacognition : Theory and Practices. International Journal Assessment in Education, 4(2), 134-148.

Schellings, G. L. M., Van Hout-Wolters, B. H. A. M., Veenman, M. V. J., \& Meijer, J. (2013). Assessing metacognitive activities: The in-depth comparison of a task-specific questionnaire with think-aloud protocols. European Journal of Psychology of Education, 28(3), 963-990. https://doi.org/10.1007/s10212-012-0149-y

Schraw, G., Crippen, K. J., \& Hartley, K. (2006). Promoting Self-Regulation in Science Education: Metacognition as Part of a Broader Perspective on Learning Gregory Schraw, Kent J. Crippen and Kendall Hartley University of Nevada. Research in Science Education, 2006(36), 111-139.

Shareeja, Ali. M. C., \& Gafoor, A. K. I. (2014). Does the Use of Metacognitive Strategies Influence Students' Problem Solving Skills in Physics? Journal Of Humanities And Social Science, 19(11), 48-51.

Siegel, M. A. (2012). Filling in the Distance Between Us: Group Metacognition During Problem Solving in a Secondary Education Course. Journal of Science Education and Technology, 21(3), 325-341.

Taasoobshirazi, G., Bailey, M., \& Farley, J. (2015). Physics Metacognition Inventory Part II : Confirmatory factor analysis and Rasch analysis Physics Metacognition Inventory Part II : Con fi rmatory factor analysis and Rasch analysis. International Journal of Science Education. https://doi.org/10.1080/09500693.2015.1104425

Taasoobshirazi, G., \& Farley, J. (2013). Construct Validation of the Physics Metacognition Inventory. International Journal of Science Education, 35(3), 447-459. https://doi.org/10.1080/09500693.2012.750433

Wall, K., \& Hall, E. (2016). Teachers as metacognitive role models. European Journal of Teacher Education ISSN: Retrieved from http://www.tandfonline.com/loi/cete20 
Zohar, A., \& Barzilai, S. (2013). Studies in Science Education A review of research on metacognition in science education : current and future directions. Studies in Science EducationStudies in Science Education, 49(2), 121-169. 